\title{
Large-eddy simulation of the ice shelf-ocean boundary layer and heterogeneous refreezing rate by sub-ice shelf plume
}

\author{
Ji Sung $\mathrm{Na}^{1}$, Taekyun $\mathrm{Kim}^{2}$, Emilia Kyung $\mathrm{Jin}^{1 *}$, Seung-Tae Yoon ${ }^{1}$, Won Sang Lee ${ }^{1}$, Sukyoung Yun ${ }^{1}$, \\ Jiyeon Lee ${ }^{1}$ \\ $5 \quad{ }^{1}$ Korea Polar Research Institute, Incheon, 21990, South Korea \\ ${ }^{2}$ Jeju National University, Jeju, 63243, South Korea \\ Correspondence to: Emilia Kyung Jin (jin@kopri.re.kr)
}

\begin{abstract}
The role of the refreezing effect in the ice shelf-ocean boundary layer (IOBL) flow with a super-cooled, plume beneath the ice shelf is investigated using the large-eddy simulation. To reveal the detailed physical processes and characteristics of the IOBL flow, a model domain is initialized and forced by in situ observations and a comparison is made between two simulations, one with the refreezing effect and one without. The simulated velocity, potential temperature, and salinity field are validated with in situ observations performed in Terra Nova Bay in the western Ross Sea in 2016/2017, confirming that the vertical structures in the simulation results agree well with observations. In particular, it is evident that, when the refreezing effect is considered, the IOBL flow can be more realistically resolved, especially upward advection from

15 the sub-ice shelf plume and the ice front eddy. Beneath the ice shelf, two district regions (the inner and outer regions) are identified based on flow characteristics and the refreezing pattern. In the inner region, stratification and stable conditions are observed with negative momentum flux and low refreezing rates. Meanwhile, in the outer region, high shear impact and unstable conditions with a heat flux of -9 to $-52 \mathrm{~W} \mathrm{~m}^{-2}$ are observed, demonstrating the high refreezing rate and the entrainment of super-cooled water from the sub-ice shelf plume. A total of $94 \%$ of the refreezing events occur in the outer region, with a maximum refreezing rate of $1.86 \mathrm{~m} \mathrm{yr}^{-1}$ at the ice front.
\end{abstract}

\section{Introduction}

The Antarctic Ice Sheet (AIS) is buttressed by floating extensions of land ice and ice shelves (Rignot et al., 2013). One of the important roles of ice shelves in controlling the mass balance of the AIS is that they can hinder the flow of inland ice into the ocean, which in turn slows sea level rise (Holland et al., 2020). Although internal glaciological stresses and surface melting may be key contributors to weakening the stability of ice shelves, the ice shelf-ocean interaction in cavities is the dominant driving force for ice thinning. However, obtaining direct access to the ocean-filled cavities beneath ice shelves from the open ocean via autonomous underwater vehicle (e.g., Jenkins et al., 2010) or through the ice by hot-water drilling (e.g., Stanton et al., 2013) requires intermediate- to large-scale logistical support depending on the size and thickness of the ice shelves, which remains challenging. 
https://doi.org/10.5194/tc-2020-166

Preprint. Discussion started: 20 July 2020

(c) Author(s) 2020. CC BY 4.0 License.

The ice shelf-ocean interaction and basal melting in sub-ice cavities can be classified into three distinct modes (Jacobs et al., 1992; Gwyther et al., 2016). Close to the groundling line, dense and salty water melts and the resultant thermohaline convection can produce refreezing at shallower locations via an 'ice-pump' mechanism (Lewis and Perkin, 1986). At intermediate depth, warm water inflows from circumpolar deep water (CDW) from the slope-front region, and at a relatively shallow depth, warm water from seasonal coastal currents or tidal pumping melts. These sub-ice shelf oceanic environment can be divided into two even broader classifications, namely "cold-water cavity" (e.g., the Larsen C, Ross, Filchner-Ronne, and Amery ice shelves) or "“warm-water cavity” (e.g., the Getz and Totten ice shelves) based on the relative temperature of the inflowing water (Joughin et al., 2012). A number of studies have reported that ice shelves in West Antarctica have been losing their mass by increased ocean melting-largely occurring in warm-water cavities—which accounted for 31\% of the total mass loss from ice shelves in West Antarctica during the past two decades (Smith et al., 2020). Even iceberg calving is another important physical process that removes mass from Antarctic ice shelves (Liu et al., 2015), the amount of mass loss through basal melting is thought to be greater than that (Gwyther et al., 2016). The basal melt rate of ice shelves is mainly determined by the heat exchange at the boundary layer between the ocean and ice, which is known as the ice shelf-ocean boundary layer (IOBL). The nature of the IOBL is highly complex and depends on the stratification of the ambient water column, the level of turbulence, the strength of tidal currents, and the roughness and slope of the ice base, among other factors

45 (Holland et al., 2020).

In the cold-water cavity where both melting and freezing take place, positively buoyant sub-ice shelf meltwater plumes created near the grounding zone can modify the stratification and heat entrainments within the IOBL through the shear impact of its momentum near the grounding zone and the ice shelf front, resulting in the change of the melting and refreezing rates (Dutrieux et al., 2013; Sansiviero et al., 2017). The stratified water column formed by the potential density difference (or

50 salinity difference) between glacial meltwater-rich water and denser continental shelf water near the grounding zone is likely responsible for preventing the heat entrainment (Begeman et al., 2018). As the sub-ice shelf plume modulates the IOBL characteristics with shear mixing, the basal melt rate can be increased by weakening a stratification and enhancing the entrainment of seawater from the outer region. At the ice shelf bottom near the ice front, increased turbulent mixing can increase the IOBL thickness, leading to changes in heat exchange and entrainment with a modification of the refreezing rate 55 (Jenkins, 2011).

Flow structure and its quantity within the IOBL beneath the ice shelf is closely related to the basal melting and refreezing rate since the IOBL is the interface linking the ice shelf and ocean, in terms of heat transfer, salt flux, and momentum change (Holland and Jenkins, 1999; Jenkins, 2016; Rees Jones and Wells, 2018). However, the flow physics and detailed mechanisms for the melting and refreezing processes within the IOBL remain unclear. The challenges in elucidating the aforementioned 60 primarily come from technical difficulties in accessing and observing the sub-ice shelf ocean cavity, more specifically the IOBL and the complexity of the flow itself, which has highly turbulent and buoyant characteristics with various spatial and temporal scales (Nicholls et al., 2006; Everett et al., 2018). Nevertheless, there are growing demands to deal with this highly 
https://doi.org/10.5194/tc-2020-166

Preprint. Discussion started: 20 July 2020

(c) Author(s) 2020. CC BY 4.0 License.

(c) (i)

complex physics, which has led researchers to introduce high-resolution turbulence models such as the large-eddy simulation (LES) which have more realistic boundary conditions constrained by in situ observations (Gayen et al., 2016).

The LES has been successfully applied to investigate the role of turbulence in the ice-ocean interaction within the IOBL for cases in Greenland (Carsey and Garwood, 1993; Denbo and Skyllingstad, 1996) and the Arctic Sea (Glendening and Burk, 1992; Glendening, 1995; Skyllingstad and Denbo, 2001; Matsumura and Ohshima, 2015; Ramudu et al. 2018; Li et al. 2018). Additionally, the LES has been used to explore the detailed processes of ice-ocean-atmosphere interaction in the vicinity of Arctic leads (Glendening and Burk, 1992; Weinbrecht and Raasch, 2001; Esau, 2007; Lupkes et al. 2008). However, applications of the LES to the sub-ice shelf interface are quite limited.

In this study, we performed large-eddy simulation experiments for the IOBL flow including the refreezing process and validated the results with in situ observation data—namely Conductivity-Temperature-Depth (CTD) and Lowered Acoustic Doppler Current Profiler (LACDP) data—collected in front of the Nansen Ice Shelf (NIS; cold-water cavity) during the Antarctic Expedition led by the Korea Polar Research Institute in January and February 2017. The main objectives of this study are to examine flow characteristics within the IOBL in this region and to determine its impacts on the refreezing rate at the bottom of the ice shelf. Given validated outputs, we were able to account for refreezing patterns, detailed flow structures including turbulent characteristics, fluxes and the relationship between the refreezing and entrainment of super-cooled water from sub-ice shelf plume within the IOBL.

Section 2 of this paper presents the governing equations (i.e., the Navier-Stokes equation and liquidus condition) for the oceanic flow with refreezing along with a detailed explanation of the simulations. Section 3 provides an overall analysis of the simulations in order to validate the LES results and determine the characteristics within the IOBL-flow velocity, potential temperature, salinity, fluxes, and turbulence statistics. Primary findings, future works, and implications of this study are summarized in Sections 4 and 5.

\section{Methodology}

\subsection{Numerical model}

To simulate the oceanic flow with refreezing, the Parallelized Large-Eddy Simulation Model (PALM) developed by Leibniz University was employed (Maronga et al., 2015; Noh et al., 2009; Raasch et al., 2001). This model solves the nonhydrostatic, Boussinesq-approximated, filtered Navier-Stokes equations with buoyancy force, Coriolis force, and subgridscale (SGS) turbulent closure. The Boussinesq approximation can be applied to flows with negligible density variation. In the time integration, the time-difference formulas were computed using the third-order Runge-Kutta method. The $5^{\text {th }}$ order upwind scheme was used to solve the flow advection (Wicker and Skamarock, 2002). The pressure was modeled by a Poisson equation, while the mass, momentum, potential temperature, and salinity conservations were governed by Eqs. (1)-(4), respectively. 
$\frac{\partial \overline{u_{k}}}{\partial x_{k}}=0$,

$95 \frac{\partial \overline{u_{l}}}{\partial t}+\frac{\partial \overline{u_{l} u_{k}}}{\partial x_{k}}=-\frac{1}{\rho} \frac{\partial \overline{\pi^{*}}}{\partial x_{k}}-\varepsilon_{i j k} f_{j} \overline{u_{k}}+\varepsilon_{i 3 k} f_{3} \overline{u_{g, k}}+g \frac{\left(\rho_{\theta}-<\rho_{\theta}>\right)}{<\rho_{\theta}>} \delta_{i 3}-\frac{\partial \tau_{k i}^{r}}{\partial x_{k}}$,

$\tau_{k i}^{r}=\tau_{k i}-\frac{1}{3} \tau_{j j} \delta_{k i}, \overline{\pi^{*}}=\overline{p^{*}}+\frac{1}{3} \tau_{j j} \delta_{k i}$,

$\frac{\partial \bar{\theta}}{\partial t}=-\frac{\partial \overline{u_{k}} \bar{\theta}}{\partial x_{k}}+\frac{\partial H_{k}}{\partial x_{k}}+Q_{\theta}, \quad \theta=\mathrm{T}\left(\frac{P_{0}}{P}\right)^{R_{d}} / C_{p}$

$\frac{\partial \overline{s a}}{\partial t}=-\frac{\partial \overline{u_{k}} \overline{S a}}{\partial x_{k}}+\frac{\partial S_{k}}{\partial x_{k}}+Q_{s a}$,

where $u_{k}$ is the flow velocity, $\rho$ is the seawater density, $\pi^{*}$ is the dynamic pressure, $\varepsilon_{i j k}$ is the Levi-Civita symbol, $f$ is the

100 Coriolis force, $\delta_{i j}$ is the Kronecker delta function, $g$ is the gravitational acceleration, $\rho_{\theta}$ is the potential density, $T$ is the absolute temperature, $v$ is the dynamic viscosity, $\tau^{r} k$ is the Reynolds stress, $\theta$ is the potential temperature, $p$ is the hydrostatic water pressure, $p_{0}$ is the reference pressure, and $S a$ is the salinity. $Q_{\theta}$ and $Q_{s a}$ are the external forcing of the source/sink terms of $T$ and $S a$, respectively. Overbars denote that the values have been filtered over the grid volume. Combining these equations, the SGS turbulent kinetic energy (e) equation [Eq. (5)] is derived as follows:

$\frac{\partial \bar{e}}{\partial t}=-\overline{u_{k}} \frac{\partial \bar{e}}{\partial x_{k}}-\tau_{k i} \frac{\partial \overline{u_{l}}}{\partial x_{k}}+\frac{g}{\theta_{0}} \overline{u^{\prime}{ }_{3} \rho^{\prime}{ }_{\theta}}-\frac{\partial}{\partial x_{k}}\left\{\overline{\left\{u_{k}^{\prime}\left(e+\frac{p^{\prime}}{\rho_{0}}\right.\right.}\right\}-\varepsilon$

where $=\frac{\bar{u}_{i} \bar{u}_{i}}{2}$, and $\varepsilon$ is the SGS dissipation rate.

The SGS stresses for the momentum, potential temperature, and salinity are parameterized as follows:

$\tau_{k i}=\overline{u_{k} u_{\imath}}-\overline{u_{k}} \overline{u_{l}}=-K_{m}\left(\frac{\partial \overline{u_{l}}}{\partial x_{k}}+\frac{\partial \overline{u_{k}}}{\partial x_{i}}\right)+\frac{2}{3} \delta_{i k} \bar{e}, \quad K_{m}=C_{m} l \sqrt{\bar{e}}$,

$H_{k}=\overline{u_{k} \theta}-\overline{u_{k}} \bar{\theta}=\overline{u_{k}^{\prime}{ }_{k}}=-K_{h}\left(\frac{\partial \bar{\theta}}{\partial x_{k}}\right), \quad K_{h}=\left(1+2 \frac{l}{\Delta}\right) K_{m}$,

$110 S_{k}=\overline{u_{k} S a}-\overline{u_{k}} \overline{S a}=\overline{u_{k}^{\prime} S a^{\prime}}=-K_{h}\left(\frac{\partial S a}{\partial x_{k}}\right)$,

$\frac{\partial}{\partial x_{k}}\left[\overline{u^{\prime}{ }_{k}\left(e+\frac{p^{\prime}}{\rho_{0}}\right)}\right]=-\frac{\partial}{\partial x_{k}} v_{e} \frac{\partial \bar{e}}{\partial x_{k}}, v_{e}=2 v_{T}$,

$\varepsilon=C_{\varepsilon} \frac{e^{3 / 2}}{l}, C_{\varepsilon}=0.19+0.74 l$,

$v_{T}=C_{m} l \sqrt{\bar{e}}$ with empirical value $C_{m}=$ constant $=0.1$, and $l=\min \left(1.8 z, \Delta, 0.76 \sqrt{\bar{e}}\left[\frac{g}{\theta} \frac{\partial \bar{\theta}}{\partial z}\right]\right)$

where $l$ is the turbulent mixing length scale and $\Delta$ is the length scale of the filter.

To resolve thermal and salt changes by the refreezing effect at the ice-ocean boundary, it is necessary to determine ambient variables $\left(\theta_{f}\right.$ and $\left.S_{f}\right)$ within the IOBL and interfacial variables $\left(\theta_{b}\right.$ and $\left.S_{b}\right)$ near the ice-ocean boundary. In this study, we determined the ambient variables based on in-situ CTD observations. To obtain interfacial variables, we solved the conservation equations of heat and salt, along with the liquidus condition and turbulent exchange velocities for heat and salt (Beckmann and Goosse, 2003; Vreugdenhil and Taylor, 2019). 
$\rho_{w} \gamma_{\theta} \frac{k_{s}}{k_{\theta}}\left(S_{f}-S_{b}\right)=\rho_{i} S_{b} r$

$\theta_{b}=-\lambda S_{b}$,

$S_{b}=\frac{-\left(\theta_{b}+\frac{L_{i} k_{S}}{c_{w k_{\theta}}}\right)+\sqrt{\left(\theta_{b}+\frac{L_{i} k_{s}}{c_{w k_{\theta}}}\right)^{2}-4 \lambda\left(\frac{L_{i} k_{s}}{c_{w k_{\theta}}}\right) s_{f}}}{-2 \lambda}$,

where $r$ is the refreezing rate, the subscript $w$ refers to parameters for water, the subscript $i$ refers to parameters for ice. The specific heat capacity of water $\left(C_{w}\right)=3974 \mathrm{~J} \mathrm{~kg}^{-1}{ }^{\circ} \mathrm{C}^{-1}$, the latent heat of fusion $(L i)=3.35 \times 10^{5} \mathrm{~J} \mathrm{~kg}^{-1}$, and $\lambda=0.054{ }^{\circ} \mathrm{C} \mathrm{psu}^{-1}$ (UNESCO, 1981). The molecular diffusivities of heat $k_{\theta}$ and salt $k_{S}$ are $1.3 \times 10^{-7} \mathrm{~m}^{2} \mathrm{~s}^{-1}$ and $7.2 \times 10^{-10} \mathrm{~m}^{2} \mathrm{~s}^{-1}$, respectively (based on Prandtl number $=14$, Schmidt number $=2,500$ in Antarctic). Grid size used in this study cannot resolve the gradients of temperature and salinity at the interface near the ice-ocean boundary, and therefore we used the turbulent exchange velocity of heat $\left(\gamma_{\theta}\right)$ which have value of $10^{-4} \mathrm{~m} \mathrm{~s}^{-1}$.

The fluxes for temperature and salinity, $q_{\theta *}$ and $q_{S^{*}}$ at ice shelf bottom are formulated by Monin-Obukhov similarity and interfacial values, $\theta_{b}$ and $S_{b}$ obtained by resulting equation, Eq (13) (McPhee et al., 1987; Ramudu et al. 2018).

$q_{\theta *}=\frac{1}{\tau_{\theta}}\left[\theta\left(z_{1}\right)-\theta_{b}\right] u_{*}$,

$q_{S *}=\frac{1}{\tau_{S}}\left[S a\left(z_{1}\right)-S_{b}\right] u_{*}$,

$\tau_{\theta, S}=\frac{1}{\kappa} \ln \left(\frac{z_{1}}{z_{0}}\right)+1.57\left(\frac{u_{*} z_{0}}{v}\right)^{1 / 2}\left(\frac{v}{k_{\theta, S}}\right)^{2 / 3}$,

\subsection{Simulation description}

In this study, we conducted two LES simulations, one with the refreezing effect and one without this effect, to reveal the role of the refreezing on IOBL characteristics. Idealized experiments were designed to resolve the IOBL flow with sub-ice shelf plume beneath the NIS with turbulence structures of various scales. The simulation dimensions were $3072 \mathrm{~m} \times 3072 \mathrm{~m}$

$140 \times 864 \mathrm{~m}$ in the $x, y$, and $z$ directions, respectively. For the simulations, a grid of $384 \times 384 \times 288$ cells was used with an $8 \mathrm{~m}$ horizontal grid and a $3 \mathrm{~m}$ vertical grid with a surface roughness of $0.07 \mathrm{~m}$. The used grid size and surface roughness were based on a numerical study of high shear plume flow and observation of surface roughness in the marginal ice zone in Greenland (McPhee et al., 1987; Gao et al., 2019). An idealized ice shelf with a depth of $280 \mathrm{~m}$ was located in the upper-left part of the simulation domain, referring to the ice shelf depth near the ice front of the NIS study (Stevens et al., 2017). For the

145 velocity, the potential temperature, and the salinity, the inlet boundary condition was set to the Dirichlet boundary condition with constant vertical profiles which was the same as the initial profiles. At the start of the simulation, initial profiles were imposed on the whole domain. Initial profiles were set in the variation range of vertical profiles of our 24 CTD and 23 LADCP observations conducted near the ice front of the NIS. The outlet boundary condition was determined to match the radiation 
https://doi.org/10.5194/tc-2020-166

Preprint. Discussion started: 20 July 2020

(c) Author(s) 2020. CC BY 4.0 License.

(c) (i)

boundary condition, which prevented numerical errors without rapid change of velocity and scalars. The cyclic boundary condition was applied to lateral boundaries, while a Dirichlet boundary condition $\left(U_{t o p}=-0.075 \mathrm{~m} \mathrm{~s}^{-1}\right)$ was imposed on the top layer. A random generator for small velocity perturbation was applied at depths from 15 to $800 \mathrm{~m}$ to quickly spin up the turbulence. The total simulation time required to reach the quasi-steady state was 86 hours. Detailed information about the simulation domain and boundary conditions is summarized in Fig. 1. This figure shows the target research region, observation points, and simulation domain with a schematic diagram for the oceanic flow with a sub-ice shelf plume. In the oceanic region, the simulated ocean velocity, potential temperature, and salinity of the LES results were validated with CTD and LADCP observations. After this validation, detailed flow characteristics of the IOBL flow beneath the ice shelf were analyzed.

\subsection{CTD, LADCP observations}

During the hydrographic survey conducted from 26 January to 15 February 2017 by the icebreaking research vessel ARAON operated by the Korea Polar Research Institute, full-depth CTD and LADCP profiles were obtained with one-hour intervals from 14 February 2017 13:00 UTC to 15 February 2017 11:55 UTC at a single site in the Terra Nova Bay in front of the NIS in order to examine the vertical structures of the super-cooled, sub-ice shelf plume with temporal variations. The exact location of the observations is $75.008^{\circ} \mathrm{S}, 163.617^{\circ} \mathrm{E}$ (Fig. 1b). Because the LADCP data was incorrectly observed at the final casting, 24 CTD profiles and 23 LADCP profiles were used in this study. The CTD data were processed following the SBE recommended procedure (Sea-Bird Electronics, Inc., Bellevue, Washington, USA; 2014) and the LADCP data were processed using the methods introduced in Thurnherr (2004). The detailed shipboard information and processing methods for the hydrographic data are described in Yoon et al. (2020).

\section{Results}

\subsection{Validation of simulation results}

Figure 2 shows the time series of the friction velocities at the ice shelf bottom, which confirms that the IOBL and oceanic flows approached a quasi-steady state. The total simulation time $(86 \mathrm{~h})$ is normalized by the large-eddy turnover time $\left(\mathrm{t}^{*}=3.29\right.$ h) which was calculated by the scale of overturning large eddy ( $864 \mathrm{~m}$ ) in the simulation domain divided by the mean velocity $\left(0.0729 \mathrm{~m} \mathrm{~s}^{-1}\right)$. Friction velocities in two cases with and without the refreezing are highly fluctuated in the whole period,

175 showing there are a large-scale eddies beneath the ice shelf. In 3-h moving average results, a convergence trend appears clearly after $17 \mathrm{t}^{*}$. Friction velocities in cases without and with refreezing are 0.00219 and $0.00283 \mathrm{~m} \mathrm{~s}^{-1}$, respectively. This difference is induced by high momentum exchange by refreezing and its brine rejection. To observe the averaged features of the flow without temporal variance in two simulation cases, we used the time-averaged results within $1 \mathrm{t}^{*}$ period in the later analysis. 
https://doi.org/10.5194/tc-2020-166

Preprint. Discussion started: 20 July 2020

(c) Author(s) 2020. CC BY 4.0 License.

(c) (i)

Figure 3 illustrates vertical sections ( $y=1536 \mathrm{~m}$, domain center) of velocity, potential temperature, and salinity which are time-averaged in $1 \mathrm{t}^{*}$ period to examine the spatial distributions of flow structures and variables in the case with refreezing effect. In Fig. 3a, vortical structures that are identified by the swirling strength criterion ( $\mathrm{s}=2 \times 10^{-7}$ ) to observe the structures of overturning eddies clearly (Na et al., 2019). Due to neutral buoyancy, sub-ice shelf plume is about $100 \mathrm{~m}$ apart from the ice shelf and has a high velocity $\left(0.05 \sim 0.08 \mathrm{~m} \mathrm{~s}^{-1}\right)$. In the IOBL beneath the ice shelf, there are various coherent structures induced by the shear impact of the sub-ice shelf plume and momentum entrainment from the upper mixed layer. Near the ice front, a large-scale eddy structure with negative mean velocity is observed. In this study, we refer to this large-scale eddy as the "ice front eddy”. This eddy is induced by strong flow shear near the ice front and unstable conditions by refreezing. The occurrence of the ice front eddy enhances the entrainment of super-cooled water from the sub-ice shelf plume, which leads to vigorous refreezing. Subsequently, the latent heat release and brine rejection caused by this vigorous refreezing affect the upper mixed layer region. This brine rejection produces a downward force which prevents the upward advection of super-cooled water from the sub-ice shelf plume in the oceanic region. In the vertical distribution of potential temperature (Fig. 3b), the sub-ice shelf plume layer and its stratified features are clearly visible, at depths from 400 to $600 \mathrm{~m}$. The active interaction between the subice shelf plume and the IOBL is focused in the upper region (> $430 \mathrm{~m}$ ) of the plume, where salinity stratification is not strongly formed. In both the ice shelf and oceanic regions, the temperature in the depth range from 280 to $400 \mathrm{~m}$ ranges from -1.95 to $-1.90{ }^{\circ} \mathrm{C}$, due to latent heat release and weak upward advection from sub-ice shelf plume. This demonstrates that the stratification is more dominant than flow shear near the ice front and play a major role in preventing flow advection from subice shelf plume.

Figure 4 also illustrates vertical sections ( $y=1536 \mathrm{~m}$, domain center) of velocity, potential temperature, and salinity in the case without the refreezing effect to evaluate the refreezing effect on the IOBL characteristics. Similar trends are observed in the cases with and without the refreezing effect, except that different temperature is observed in the upper mixed layer and different patterns of upward flow advection from sub-ice shelf plume are observed. Since there is no downward force due to brine rejection, the upper region of the sub-ice shelf plume expanded to the upward direction immediately after it passed the ice front. In the oceanic region, the temperature in the upper mixed layer is from -1.99 to $-1.96{ }^{\circ} \mathrm{C}$ due to the lack of latent heat release and the strong upward advection.

In the LES model, the filtered Navier-Stokes equation is solved with the modelled effect of small-scale eddies to reduce computational cost. Therefore, the criteria for "small-scale" are important; these criteria are determined by grid size. To evaluate grid size and modelling of small-scale eddies in this study, it is necessary to confirm that the turbulence characteristics of the LES result are similar to the turbulence characteristics of inertial subrange in which energy cascading occurred with few dissipations. Figure 5 shows plots of the one-dimensional energy spectra at different depths where flow shear is strong in the LES results with and without the refreezing effect. In the overall range of wavenumbers, in cases with and without refreezing, energy spectra follow the $-5 / 3$ slope of the Kolmogorov scale in the inertial subrange. At high wavenumbers, at similar magnitude of the energy spectra is observed in cases with and without the refreezing effect with a slight underestimation of turbulence energy in SGS turbulence. At low wavenumbers, the energy spectra in the case without refreezing are higher than 
https://doi.org/10.5194/tc-2020-166

Preprint. Discussion started: 20 July 2020

(c) Author(s) 2020. CC BY 4.0 License.

(c) (i)

those in the case with refreezing, showing that strong turbulence energy is developed with expanded upper region of sub-ice shelf plume in the case without the refreezing effect.

Figure 6 plots the vertical profiles of the stream-wise zonal velocity, potential temperature, and salinity in the LES results and CTD and LADCP observations to quantitatively compare the vertical distribution of the momentum and variables related to potential density. The initial profiles of observed velocity, potential temperature, and salinity used for domain initialization and the inlet boundary condition are compared with the LES results to observe how the LES results are adjusted under the geometrical effect of the ice shelf and boundary conditions. In the velocity profiles, the LES results with and without the refreezing effect agree well with the 23 LADCP profiles, except for slight difference in the velocity magnitude and the depth of the peak induced by the difference in upward advection and downward force caused by brine rejection. Due to this difference, the magnitudes of potential temperature in the upper mixed layer in the cases with and without refreezing are quite different: in the upper mixed layer, the potential temperature in the case without refreezing is about $-1.97{ }^{\circ} \mathrm{C}$, whereas that in the case with refreezing is about $-1.94{ }^{\circ} \mathrm{C}$, which is closer to the CTD observation results. This difference is due to the latent heat of refreezing at the ice shelf bottom and the weak upward advection in the case with the refreezing effect, which is close to reality. Regarding the salinity profiles, the two LES results agree with the 24 CTD profiles. However, the multi-layered stratified characteristics of the salinity profile at depth of ice shelf bottom and IOBL top are observed in the case with refreezing effect. Through the comparison of quantity and its characteristics, we conclude that the LES results with the refreezing effect are similar to in situ observations of oceanic environments. However, it should be noted that, since this is an idealized model, some differences can be expected between the simulated results and observations, in terms of ice shelf bathymetry and surface roughness, the temporal variability of the sub-ice water plume, the drag effect of frazil ice, etc.

\subsection{IOBL characteristics in the sub-ice environment}

Through the afore-mentioned analysis, it is shown that the LES model adequately resolves the oceanic flow beneath the ice shelf with the proper refreezing effect beneath the ice shelf. Next, we explores the flow characteristics of the IOBL beneath the ice shelf using the validated LES results. Within the IOBL, there are the shear forces caused by the momentum of the subice shelf plume and the buoyancy force (stratification) caused by the vertical gradient of potential density. In this section, we analyze the detailed flow physics within the IOBL to reveal the relationship between the flow physics and refreezing patterns within the IOBL beneath the ice shelf.

Figure 7 illustrates the horizontal distributions of $1 \mathrm{t}^{*}$ time-averaged vertical velocity and the normalized refreezing rate at a depth of $281 \mathrm{~m}$, which is the nearest depth to the ice shelf bottom. In this study, we define the inner region $(0 \sim 640 \mathrm{~m})$ and outer region ( $640 \sim 1,280 \mathrm{~m}$, ice front) at the ice shelf bottom based on the refreezing pattern and ice front eddy. As shown in Fig. 7, different features of vertical velocity and refreezing are observed in the inner and outer regions. For example, unlike in the inner region, small-scale structures that are detected in vertical velocity structures are concentrated in the outer region, especially in the distance range from 1050 to $1280 \mathrm{~m}$. Additionally, meridional direction-stretched structures are observed at 
https://doi.org/10.5194/tc-2020-166

Preprint. Discussion started: 20 July 2020

(c) Author(s) 2020. CC BY 4.0 License.

the interface between the inner and outer regions. Since, these structures are mainly induced by the ice front eddy, these have a role of negative heat flux from the IOBL to the ice shelf and the entrainment of super-cooled water, resulting in vigorous refreezing near the ice front.

Figure 8 plots the zonal distributions of the normalized refreezing rate and heat flux at a depth of $281 \mathrm{~m}$ to quantitatively demonstrate the heterogeneous distribution of the normalized refreezing rate. A low negative heat flux and refreezing rate are observed in the inner region. Meanwhile, a high negative heat flux is observed near the ice front, which causes the refreezing rate in the outer region to increase rapidly; the results show that $94 \%$ of the total refreezing rate occurred in the outer region. The maximum refreezing rate $\left(r_{\max }\right)$ which is observed at the ice front is $1.86 \mathrm{~m} \mathrm{yr}^{-1}$. The main factors that determine the magnitude and distribution of the refreezing rate are the ice front eddy and the entrainment of super-cooled water.

Figure 9 plots vertical profiles of the mean velocity and turbulence intensity in the inner and outer regions to obtain insight into the stochastic characteristics of the ice front eddy and negative heat flux in the IOBL. Near the ice shelf bottom, there is negative zonal velocity in the outer region due to refreezing and the strong shear force near the ice front, having a steep velocity gradient. In contrast, the zonal velocity in the inner region has almost zero magnitude. Turbulence intensity is the second moment of velocity and represents the magnitude of the mixing by the advective motion of the flow. Owing to a steep velocity gradient, the IOBL turbulence intensity in the outer region is almost twice as high as that in the inner region. This means that the IOBL in the outer region is an effective environment to elevate super-cooled water from the sub-ice shelf plume to the IOBL.

Figure 10 shows the vertical profiles of momentum and heat fluxes within the IOBL. As shown in figure, the depth of the IOBL top (438 $\mathrm{m}$ ) is determined to be the depth where the magnitude of the heat flux is $1 \%$ of the maximum heat flux induced by the sub-ice shelf plume. In the vertical momentum flux in the inner region, negative flux induced by refreezing and stratification is observed, showing that the IOBL flow in the inner region is in a stable condition. However, positive flux with large-scale advection (IOBL scale) induced by the ice front eddy is observed in the outer region, showing that the IOBL flow in the outer region is in an unstable condition. Near the ice shelf bottom in the outer region, small-scale structures $(\sim 10 \mathrm{~m}$, shown in Fig. 7a) are developed, having the negative heat flux which represents negative heat transfer from the IOBL to the ice shelf for refreezing. In the depth range from 280 to $320 \mathrm{~m}$, negative heat fluxes vary from -9 to $-52 \mathrm{~W} \mathrm{~m}^{-2}$. This range is comparable with the order of the negative heat flux in frazil ice formations beneath sea ice near the Ross Sea (Langhomrne et al., 2017). This suggests that there is a frazil ice layer and refreezing between depths of 280 and $320 \mathrm{~m}$ in the outer region. From depths of 390 to $440 \mathrm{~m}$, another negative heat flux is developed by the ice front eddy, which causes the entrainment of super-cooled water from sub-ice shelf plume to IOBL the flow.

Figure 11 plots vertical profiles of the flatness factor of vertical velocity and the probability density function at the depth where the peak flatness occur. The flatness factor is the fourth moment of velocity and represents the possibility and frequency of high magnitude events. The spatial distribution of the velocity magnitude is almost homogeneous, showing flatness factors within the IOBL in the inner region is in the range of 2.6-3.8, which corresponds to a Gaussian distribution. However, within the IOBL in the outer region, the flatness factor is in the range of 4.4-5.6 and its peak occurs at a depth of $416 \mathrm{~m}$, close to the 
https://doi.org/10.5194/tc-2020-166

Preprint. Discussion started: 20 July 2020

(c) Author(s) 2020. CC BY 4.0 License.

(c) (i)

280 top of the IOBL. As shown in the inset graph of Fig. 11, the fluctuation of vertical velocity at a depth of $416 \mathrm{~m}$ in the inner region has $3 \sigma$, which corresponds to moderate magnitude events, while that in the outer region has $6-10 \sigma$, which corresponds to high magnitude events. These high magnitude events are also induced by the ice front eddy and large-scale advection near the ice front.

\section{Discussions}

\subsection{LES simulation for IOBL flow}

The main processes of the ice-ocean interactions related with ice mass balance in cold-water cavity are basal melting near the grounding zone and refreezing near the ice front (Dinniman et al., 2016; Jacob et al., 1992; Petty et al., 2013). One of these processes is triggered by the intrusion of the High Salinity Shelf Water (HSSW). When this dense seawater intrudes into the ocean-filled cavity beneath the ice shelf, the base of the deep ice shelf is melted because the temperature of the HSSW is higher than the freezing temperature at this depth. Then, super-cooled, less-dense water is formed at the base of the deep ice shelf and rise, creating the sub-ice shelf plume with high momentum and buoyancy. This water plume refreezes in the outer cavity region or near the ice front with increased freezing temperature and forms platelet ice (Galton-Fenzi et al., 2012; Robinson et al., 2014).

During these processes, the IOBL flow and its turbulence structures have a crucial role in mass and energy transport in Antarctic oceanic flow. Additionally, these are key to explaining and evaluating the complex phenomenon of ice-ocean interaction beneath the ice shelf. Therefore, it is necessary to investigate the detailed structures and their physical processes to follow the trajectory of mass and energy. Understanding the flow physics and structures using only the one-dimensional profile obtained by CTD and LADCP has many limitations. Moreover, the observational approach is difficult in sub-ice shelf environments. As shown in previous LES studies of ice-ocean boundary (Ramudu et al. 2018; Vreugdenhil and Taylor, 2019), the LES model is a powerful tool for resolving the flow and its three-dimensional structures with the change of mass and energy, with high accuracy and low computational cost. Therefore, when employing the numerical approach including the LES, a regional ocean model is one of the solutions for resolving the three-dimensional structures in the oceanic flow. In this study, we used the LES model to expand the one-dimensional observation profile in oceanic region to the three-dimensional

305 flow-field in oceanic region and the sub-ice shelf region. Additionally, we set to ambient values $\left(\theta_{f}\right.$, $\left.S_{f}\right)$ by using the CTD results to obtain the interfacial values $\left(\theta_{b}, S_{b}\right)$ in the liquidus condition. We assumed that the LES results for the sub-ice shelf region are validated if the LES results for the oceanic region are validated. Via an evaluation of the refreezing effect, we obtained a successful validation for the oceanic region (Fig. 6). In future work, this methodology will be validated using multidimensional sub-ice shelf observation methods such as autonomous underwater vehicle (AUV), glider instruments, etc. 
https://doi.org/10.5194/tc-2020-166

Preprint. Discussion started: 20 July 2020

(c) Author(s) 2020. CC BY 4.0 License.

(c) (i)

\subsection{IOBL characteristics in the sub-ice environment}

The characteristics of the IOBL are more complex than the oceanic characteristics in the upper mixed layer since brine rejection and latent heat release by refreezing at the ice shelf bottom affect the density inversion and advection magnitude within the IOBL. In this study, our main findings were the heterogeneous distribution of the refreezing rate and its causes

315 within the sub-ice shelf environment. Moreover, we quantified important values such as the scale of ice front eddy, the IOBL depth, negative heat transfer, and the refreezing distribution. The results of this study will be used to interpret an insufficient amount of information obtained by limited observation of the sub-ice shelf cavity. If direct observation for IOBL flow structures and turbulence characteristics in sub-ice shelf environment is available, this study can be improved by comparing LES results with observations and its feedback. Other important factors which were not included in this study should be addressed and investigated in future studies-e.g., the effect of ice shelf bathymetry and surface roughness on shear characteristics, the temporal variability of the sub-ice water plume, and the drag effect of frazil ice. If a database for flow physics in various parameters is completed, these studies can be used for the improvement of parameterizations (e.g. vertical mixing within the IOBL, sea-ice formation and behavior) in the regional ocean model.

\section{Conclusions}

We successfully simulated the IOBL flow with a super-cooled, sub-ice shelf plume and the refreezing effect beneath the NIS using a large-eddy simulation and boundary conditions based on in-situ observations. The flow performed for $86 \mathrm{~h}(23 \mathrm{t} *)$ reaches a quasi-steady state after $17 \mathrm{t}^{*}$, showing the convergence trend in temporal variance. To validate the LES results with and without the refreezing effect, the simulated velocity, potential temperature, and salinity are compared with 24-hour CTD and LADCP observations obtained near the NIS in Terra Nova Bay of the western Ross Sea in a 2016/2017 shipboard survey. The simulation results agree well with the observations in terms of magnitude and the slope and the depth of peak values, except for the temperature difference in the upper mixed layer. Based on this validation, we conclude that the LES results with the refreezing effect better resolve the Antarctic environment in the NIS, especially the upward advection from the sub-ice shelf plume. In the one-dimensional energy spectra, the slope of the energy spectra in the overall wavenumber range follows the $-5 / 3$ slope which corresponds to the Kolmogorov scale in the inertial subrange, except that SGS turbulence energy is underestimated in the low wavenumber range. In the IOBL flow beneath the ice shelf, two distinct regions (an inner region and an outer region) can be identified based on the refreezing rate and flow physics. Stratification and stable conditions caused by refreezing and weak upward advection from the sub-ice shelf plume are observed within the IOBL in the inner region.

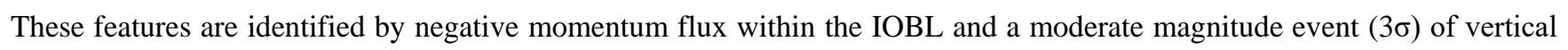

340 velocity at the top of the IOBL. However, unstable features by strong shear of ice front eddy and refreezing are observed within the IOBL in the outer region, showing the occurrence of high magnitude event $(>6 \sigma)$ of vertical velocity caused by the entrainment of super-cooled water from sub-ice shelf plume. These different features in the two regions yield the heterogeneous 
https://doi.org/10.5194/tc-2020-166

Preprint. Discussion started: 20 July 2020

(c) Author(s) 2020. CC BY 4.0 License.

(c) (i)

distribution of the refreezing rate. A total of $94 \%$ of the total refreezing is concentrated in the outer region, having a maximum refreezing rate of $1.86 \mathrm{~m} \mathrm{yr}^{-1}$ at the ice front.

\section{Acknowledgments}

This work was sponsored by a research grant from the Korean Ministry of Oceans and Fisheries (KIMST20190361; PM19020).

\section{References}

Begeman, C. B., Tulaczyk, S. M., Marsh, O. J., Mikucki, J. A., Stanton, T. P., Hodson, T. O., Siegfried, M. R., Powell, R.

D., Christianson, K. and King, M. A.: Ocean Stratification and Low Melt Rates at the Ross Ice Shelf Grounding Zone, J. Geophys. Res. Oceans, 123(10), 7438-7452, doi:10.1029/2018JC013987, 2018.

Carsey, F. D. and Garwood, Jr. R. W.: Identification of modeled ocean plumes in Greenland Gyre ERS-1 SAR data, Geophys. Res. Lett., 20, 2207-2210, doi:10.1029/93GL01954, 1993.

Denbo, D. W. and Skyllingstad E. D.: An ocean large-eddy simulation model with application to deep convection in the

Greenland Sea, J. Geophys. Res.,101, 1095-1110, doi:10.1029/95JC02828, 1996.

Dinniman, M. S., Asay-Davis, X. S., Galton-Fenzi, B. K., Holland, P. R., Jenkins, A. and Timmermann, R.: Modeling ice shelf/ocean interaction in Antarctica: A review, Oceanography, 29(4), 144-153, doi:10.5670/oceanog.2016.106, 2016.

Dutrieux, P., Vaughan, D. G., Corr, H. F., Jenkins, A., Holland, P. R., Joughin, I. and Fleming, A. H.: Pine Island glacier ice shelf melt distributed at kilometre scales. Cryosphere, 7, 1543-1555, doi:10.5194/tc-7-1543-2013, 2013.

360 Everett, A., Kohler, J., Sundfjord, A., Kovacs, K. M., Torsvik, T., Pramanik, A., Boehme, L. and Lydersen, C.: Subglacial discharge plume behaviour revealed by CTD-instrumented ringed seals, Sci. Rep., 8(1), 13467, doi:10.1038/s41598-01831875-8, 2018.

Galton-Fenzi, B. K., Hunter, J. R., Coleman, R., Marsland, S. J. and Warner, R. C.: Modeling the basal melting and marine ice accretion of the Amery Ice Shelf, J. Geophys. Res. Oceans, 117(C9), doi:10.1029/2012JC008214, 2012.

365 Gao, X., Dong, C., Liang, J., Yang, J., Li, G., Wang, D. and McWilliams, J. C.: Convective instability-induced mixing and its parameterization using large eddy simulation, Ocean Model., 137, 40-51, 2019, doi:10.1016/j.ocemod.2019.03.008, 2019.

Gayen, B., Griffiths, R. W. and Kerr, R. C.: Simulation of convection at a vertical ice face dissolving into saline water, J. Fluid Mech., 798, 284-298, doi:10.1017/jfm.2016.315, 2016.

Glendening, J. W.: Horizontally integrated atmospheric heat flux from an Arctic lead, J. Geophys. Res., 100, 4613 - 4621, doi: doi:10.1029/94JC02424, 1995.

Glendening, J. W. and Burk, S. D.: Turbulent transport from an Arctic lead: A large-eddy simulation, Boundary Layer Meteorol., 59, 315-339, doi:10.1007/BF02215457, 1992. 
https://doi.org/10.5194/tc-2020-166

Preprint. Discussion started: 20 July 2020

(c) Author(s) 2020. CC BY 4.0 License.

Gwyther, D. E., Cougnon, E. A., Galton-Fenzi, B. K., Roberts, J. L., Hunter, J. R., and Dinniman, M. S.: Modelling the response of ice shelf basal melting to different ocean cavity environmental regimes, Ann. Glaciol., 57(73), 131-141, doi:10.1017/aog.2016.31, 2016.

Holland, D. M., Nicholls, K. W. and Basinski, A.: The Southern Ocean and its interaction with the Antarctic Ice Sheet, Science, 367(6484), 1326-1330, doi: 10.1126/science.aaz5491, 2020.

Holland, D. M. and Jenkins, A.: Modeling thermodynamic ice-ocean interactions at the base of an ice shelf, J. Phys. Oceanogr., 29(8), 1787-1800, doi:10.1175/1520-0485(1999)029<1787:MTIOIA>2.0.CO;2, 1999.

Jacobs, S. S., Helmer, H. H., Doake, C. S. M., Jenkins, A. and Frolich, R. M.: Melting of ice shelves and the mass balance of Antarctica, J. Glaciol., 38(130), 375-387, doi:10.3189/S0022143000002252, 1992.

Jenkins, A.: Convection-driven melting near the grounding lines of ice shelves and tidewater glaciers, J. Phys. Oceanogr., 41(12), 2279-2294, doi: 10.1175/JPO-D-11-03.1, 2011.

Jenkins, A.: A simple model of the ice shelf-ocean boundary layer and current. J. Phys. Oceanogr., 46(6), 1785-1803, doi: 10.1175/JPO-D-15-0194.1, 2016.

Jenkins, A., Dutrieux, P., Jacobs, S. S., McPhail, S. D., Perrett, J. R., Webb, A. T. and White, D.: Observations beneath Pine Island Glacier in West Antarctica and implications for its retreat, Nat. Geosci., 3(7), 468-472, doi:10.1038/ngeo890, 2010

Joughin, I., Alley, R. B. and Holland, D. M.: Ice-Sheet Response to Oceanic Forcing. Science, 338(6111), 1172-1176, doi:10.1126/science.1226481, 2012.

390 Langhorne, P. J., Hughes, K. G., Gough, A. J., Smith, I. J., Williams, M. J. M., Robinson, N. J., Stevens, C. L., Rack, W., Price, D., Leonard, G. H., Mahoney, A. R., Haas, C. and Haskell, T. G.: Observed platelet ice distributions in Antarctic sea ice: An index for ocean-ice shelf heat flux, Geophys. Res. Lett., 42(13), 5442-5451, doi:10.1002/2015GL064508, 2015.

Li, B. R., Wang, M. M., Lu, X. Y., Wan, Z. H. and Song, H. E.: Effect of Salinity on Sea Ice Motion. Therm. Sci., 22(4), 1563-1570, doi:10.2298/TSCI1804563L, 2018.

Liu, Y., Moore, J. C., Cheng, X., Gladstone, R. M., Bassis, J. N., Liu, H., et al.: Ocean-driven thinning enhances iceberg calving and retreat of Antarctic ice shelves. Proc. Natl. Acad. Sci. 112, 3263-3268, doi:10.1073/pnas.1415137112, 2015.

Maronga, B., Gryschka, M., Heinze, R., Hoffmann, F., Kanani-Sühring, F., Keck, M., Ketelsen, K., Letzel, M. O., Sühring. M. and Raasch, S.: The Parallelized Large-Eddy Simulation Model (PALM) version 4.0 for atmospheric and oceanic flows: model formulation, recent developments, and future perspectives, Geosci. Model Dev., 8, 2515-2551, doi:10.5194/gmdd-8400 1539-2015, 2015.

McPhee, M. G., Maykut, G. A. and Morison, J. H.: Dynamics and thermodynamics of the ice/upper ocean system in the marginal ice zone of the Greenland Sea, J. Geophys. Res., 92, 7017-7031, doi:10.1029/JC092iC07p07017, 1987.

Matsumura, Y. and Ohshima, K. I.: Lagrangian modelling of frazil ice in the ocean, Ann. Glaciol., 56(69) 373-382, doi:10.3189/2015AoG69A657, 2015.

405 Na, J. S., Koo, E., Ko, S. C., Linn, R., Muñoz-Esparza, D., Jin, E. K. and Lee, J. S.: Stochastic characteristics for the vortical structure of a 5-MW wind turbine wake, Renew. Energy, 133, 1220-1230, doi: 10.1016/j.renene.2018.08.088, 2019. 
https://doi.org/10.5194/tc-2020-166

Preprint. Discussion started: 20 July 2020

(c) Author(s) 2020. CC BY 4.0 License.

Nicholls, K. W., Abrahamsen, E. P., Buck, J. J. H., Dodd, P. A., Goldblatt, C., Griffiths, G., Heywood, K. j., Hughes, N. E., Kalezky, A., Lane-Serff, G. F., McPhail, S. D. Millard, N. W., Oliver, K. I. C., Perrett, J., Price, M. R., Pudsey, C. J., Saw, K, Stansfield, K., Stott, M. J., Wadhams, P., Webb, A. T. and Wilkinson, J. P.: Measurements beneath an Antarctic ice shelf using an autonomous underwater vehicle, Geophys. Res. Lett., 33(8), doi:10.1029/2006GL025998, 2016.

Noh, Y., Goh, G., Raasch, S. and Gryschka, M.: Formation of a diurnal thermocline in the ocean mixed layer simulated by LES, J. Phys. Oceanogr., 39(5), 1244-1257, doi:10.1175/2008JPO4032.1, 2009.

Petty, A. A., Feltham, D. L. and Holland, P. R.: Impact of atmospheric forcing on Antarctic continental shelf water masses, J. Phys. Oceanogr., 43(5), 920-940, doi:10.1175/JPO-D-12-0172.1, 2013.

415 Raasch, S. and Schröter, M.: PALM-a large-eddy simulation model performing on massively parallel computers, Meteorol. Z., 10(5), 363-372, doi:10.1127/0941-2948/2001/0010-0363, 2001.

Ramudu, E., Gelderloos, R., Yang, D., Meneveau, C. and Gnanadesikan, A.: Large eddy simulation of heat entrainment under arctic sea ice, J. Geophys. Res. Oceans, 123, 287-304, doi:10.1002/2017JC013267, 2018.

Rees Jones, D. and Wells, A.: Frazil-ice growth rate and dynamics in mixed layers and sub-ice-shelf plumes, Cryosphere, 12, 25-38. doi:10.5194/tc-12-25-2018, 2018.

Rignot, E., Jacobs, S., Mouginot, J. and Scheuchl, B.: Ice-shelf melting around Antarctica, Science, 341(6143), 266-270, doi:10.1126/science.1235798, 2013.

Robinson, N. J., Williams, M. J., Stevens, C. L., Langhorne, P. J. and Haskell, T. G.: Evolution of a supercooled Ice Shelf Water plume with an actively growing subice platelet matrix. J. Geophys. Res. Oceans, 119(6), 3425-3446, doi:10.1002/2013JC009399, 2014.

Sansiviero, M., Maqueda, M. M., Fusco, G., Aulicino, G., Flocco, D. and Budillon, G. Modelling sea ice formation in the Terra Nova Bay polynya. Journal of Marine Systems, 166, 4-25, doi:10.1016/j.jmarsys.2016.06.013, 2017.

SeaBird Electronics, Inc.: Seasoft V2: SBE data processing (User’s Manual, pp. 1-174). Bellevue, Washington, USA, 2014. Sharqawy, M. H., Lienhard, J. H. and Zubair, S. M.: Thermophysical properties of seawater: a review of existing correlations and data. Desalination and water treatment, 16(1-3), 354-380, doi:10.5004/dwt.2010.1079, 2010.

Skyllingstad, E. D. and Denbo, D. W.: Turbulence beneath sea ice and leads: a coupled sea ice/large eddy simulation study, J. Geophys. Res., 106(C2), 2477-2497, doi:10.1029/1999JC000091, 2001.

Smith, B., Fricker, H. A., Gardner, A. S., Medley, B., Nilsson, J., Paolo, F. S., Holschuh, N., Adusumilli, S., Brunt, K., Csatho, B., Harbeck, K., Markus, T., Neumann, T., Siegfried, M. R., and Zwally, H. J.: Pervasive ice sheet mass loss reflects competing ocean and atmosphere processes. Science, eaaz5845, doi:10.1126/science.aaz5845, 2020.

Stanton, T. P., Shaw, W. J., Truffer, M., Corr, H. F. J., Peters, L. E., Riverman, K. L., Bindschadler, R., Holland, D. M., and Anandakrishnan, S.: Channelized Ice Melting in the Ocean Boundary Layer Beneath Pine Island Glacier, Antarctica. Science, 341(6151), 1236-1239, doi: 10.1126/science.1239373, 2013.

Stevens, C., Lee, W. S., Fusco, G., Yun, S., Grant, B., Robinson, N. and Hwang, C. Y.: The influence of the Drygalski Ice 440 Tongue on the local ocean, Ann. Glaciol., 58(74), 51-59, doi:10.1017/aog.2017.4, 2017. 
https://doi.org/10.5194/tc-2020-166

Preprint. Discussion started: 20 July 2020

(c) Author(s) 2020. CC BY 4.0 License.

Thurnherr, A. M.: How to Process LADCP Data with the LDEO Software. New York: Columbia University. ftp://ftp.ldeo.columbia.edu/pub/LADCP/HOWTO/LDEO_IX.pdf, 2014.

UNESCO: Tenth report of the Joint Panel on Oceanographic Tables and Standards, Unesco Tech. Pap. in Mar. Sci. 36, 1981.

Vreugdenhil, C. A., and Taylor, J. R.: Stratification effects in the turbulent boundary layer beneath a melting ice shelf: Insights 445 from resolved large-eddy simulations, J. Phys. Oceanogr., 49(7), 1905-1925, doi:10.1175/JPO-D-18-0252.1, 2019.

Wicker, L. J. and Skamarock, W. C.: Time-splitting methods for elastic models using forward time schemes, Mon. Weather Rev., 130(8), 2088-2097, doi:10.1175/1520-0493(2002)130<2088:TSMFEM>2.0.CO;2, 2002.

Yoon, S. T., Lee, W. S., Stevens, C., Jendersie, S., Nam, S., Yun, S., Hwang, C. Y., Jang, G. I., and Lee, J.: Variability in high-salinity shelf water production in the Terra Nova Bay polynya, Antarctica, Ocean Sci., doi:10.5194/os-16-373-2020, 2020. 450 
https://doi.org/10.5194/tc-2020-166

Preprint. Discussion started: 20 July 2020

(c) Author(s) 2020. CC BY 4.0 License.
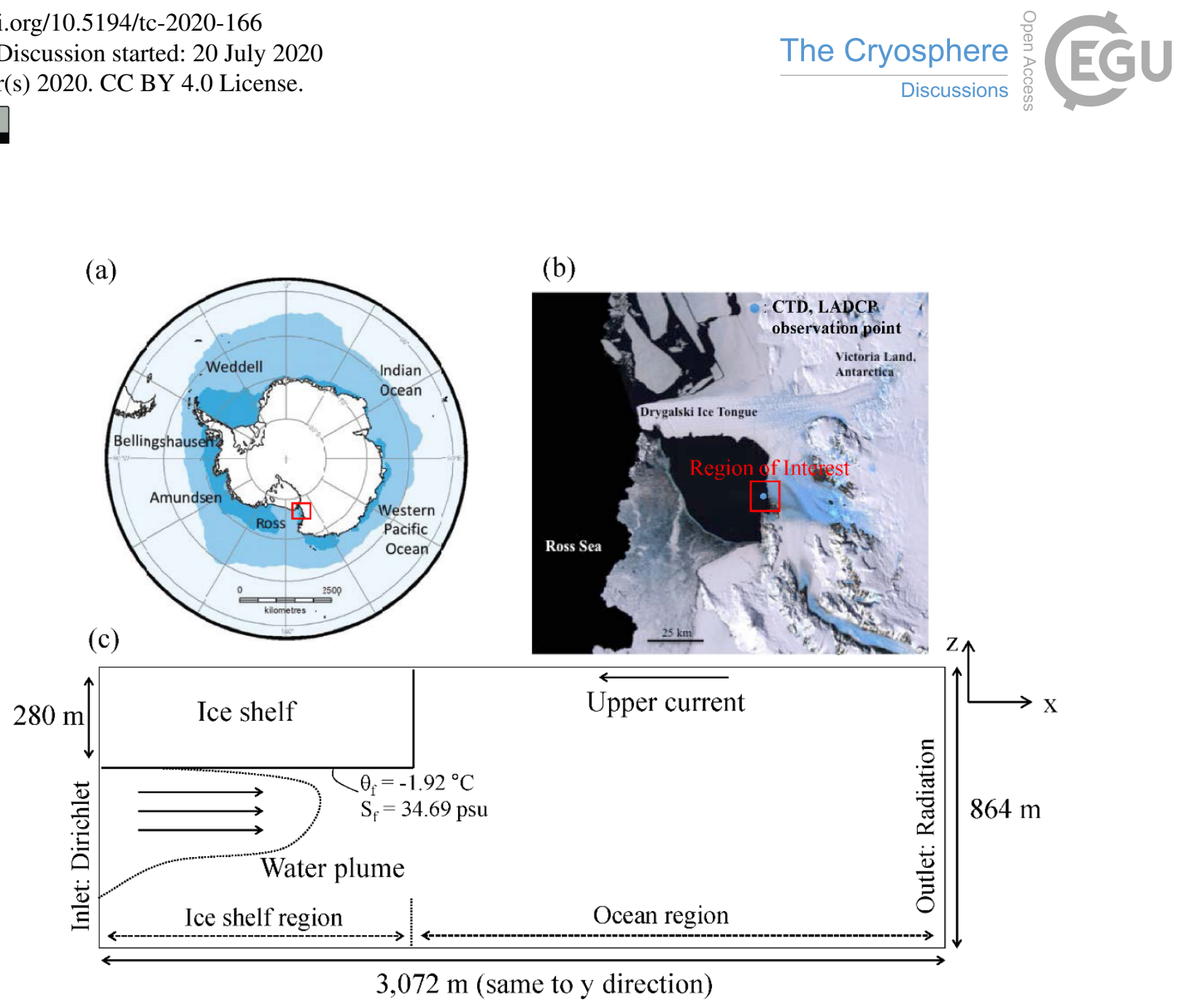

Figure 1: Region of interest and configuration of simulation domain. (a) Map of Antarctica. The red box shows the study area of 460 Terra Nova Bay in the western Ross Sea. (b) Region of interest where Conductivity-Temperature-Depth (CTD) and Lowered Acoustic Doppler Current Profiler (LADCP) surveys were conducted in the 2016/17 shipboard survey. (c) Simulation domain and boundary conditions. 
https://doi.org/10.5194/tc-2020-166

Preprint. Discussion started: 20 July 2020

(c) Author(s) 2020. CC BY 4.0 License.

The Cryosphere

Discussions

(c) (i)

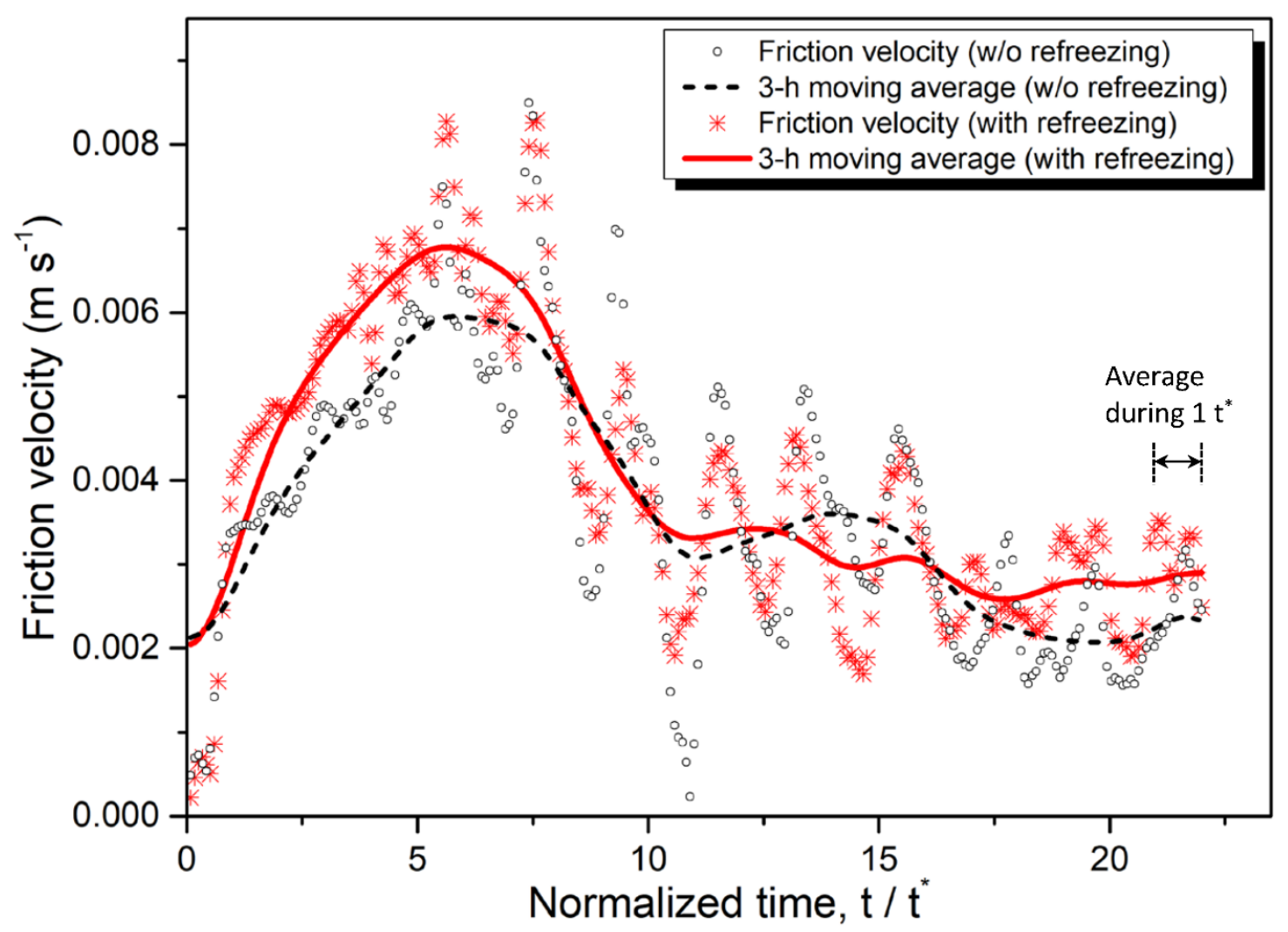

Figure 2: Time series of friction velocities in the cases with and without refreezing. The total time was normalized by large-eddy 465 turnover time, $\mathrm{t}^{*}(3.29 \mathrm{~h})$, which was calculated by overturning eddy scale $(\sim 864 \mathrm{~m})$ divided by mean velocity $\left(0.0729 \mathrm{~m} \mathrm{~s} \mathrm{~s}^{-1}\right)$. 
https://doi.org/10.5194/tc-2020-166

Preprint. Discussion started: 20 July 2020

(c) Author(s) 2020. CC BY 4.0 License.
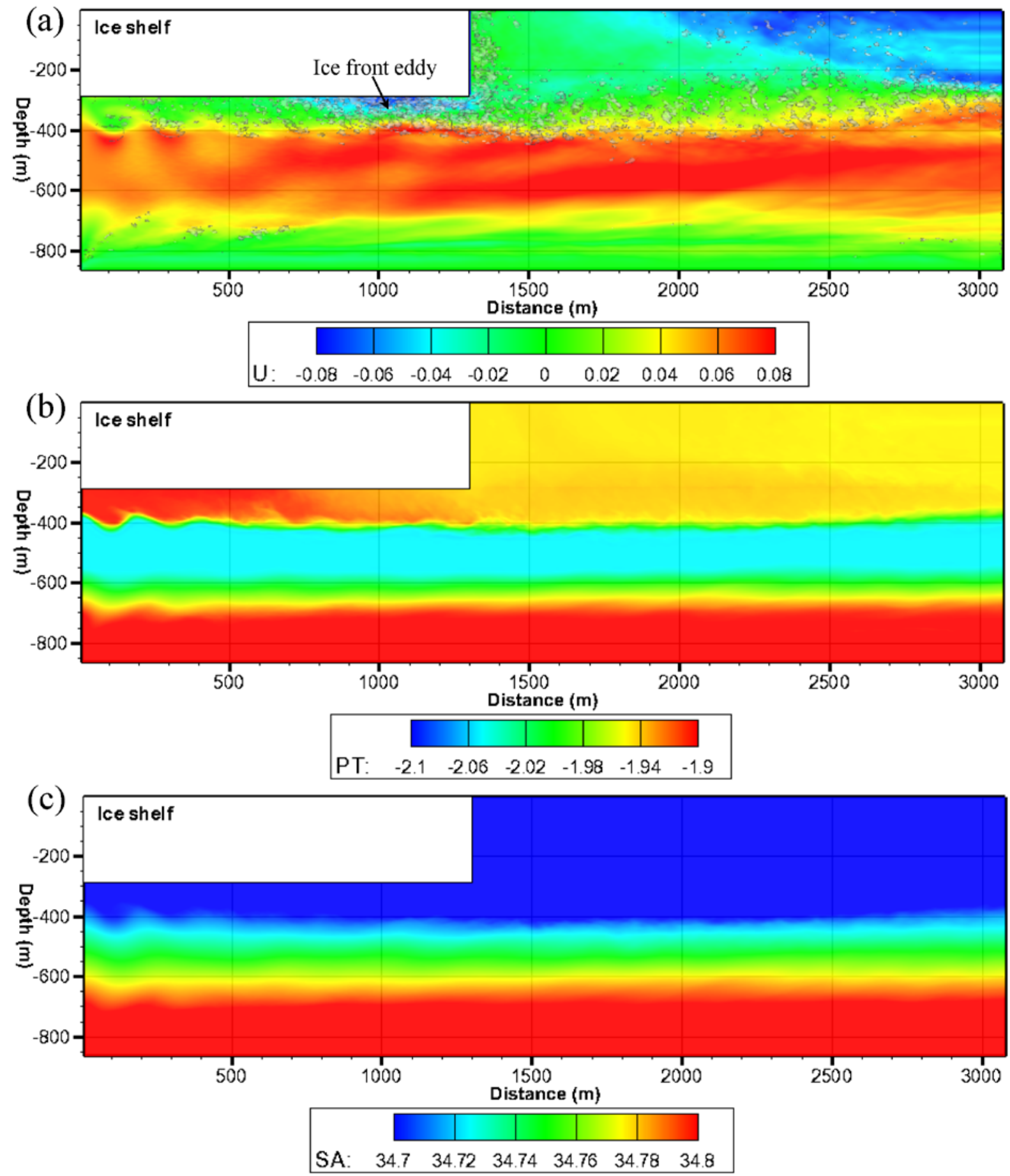

Figure 3: $x z$ cross-section contours $(y=1,536 \mathrm{~m}$, domain center) of zonal velocity, potential temperature, and salinity in the case with the refreezing effect. These results were time-averaged in the last one $t^{*}$ period. (a) zonal velocity with vortical structures that were identified by using the swirling strength criterion $\left(s=2 \times 10^{-7}\right)$, (b) potential temperature, and (c) salinity. 

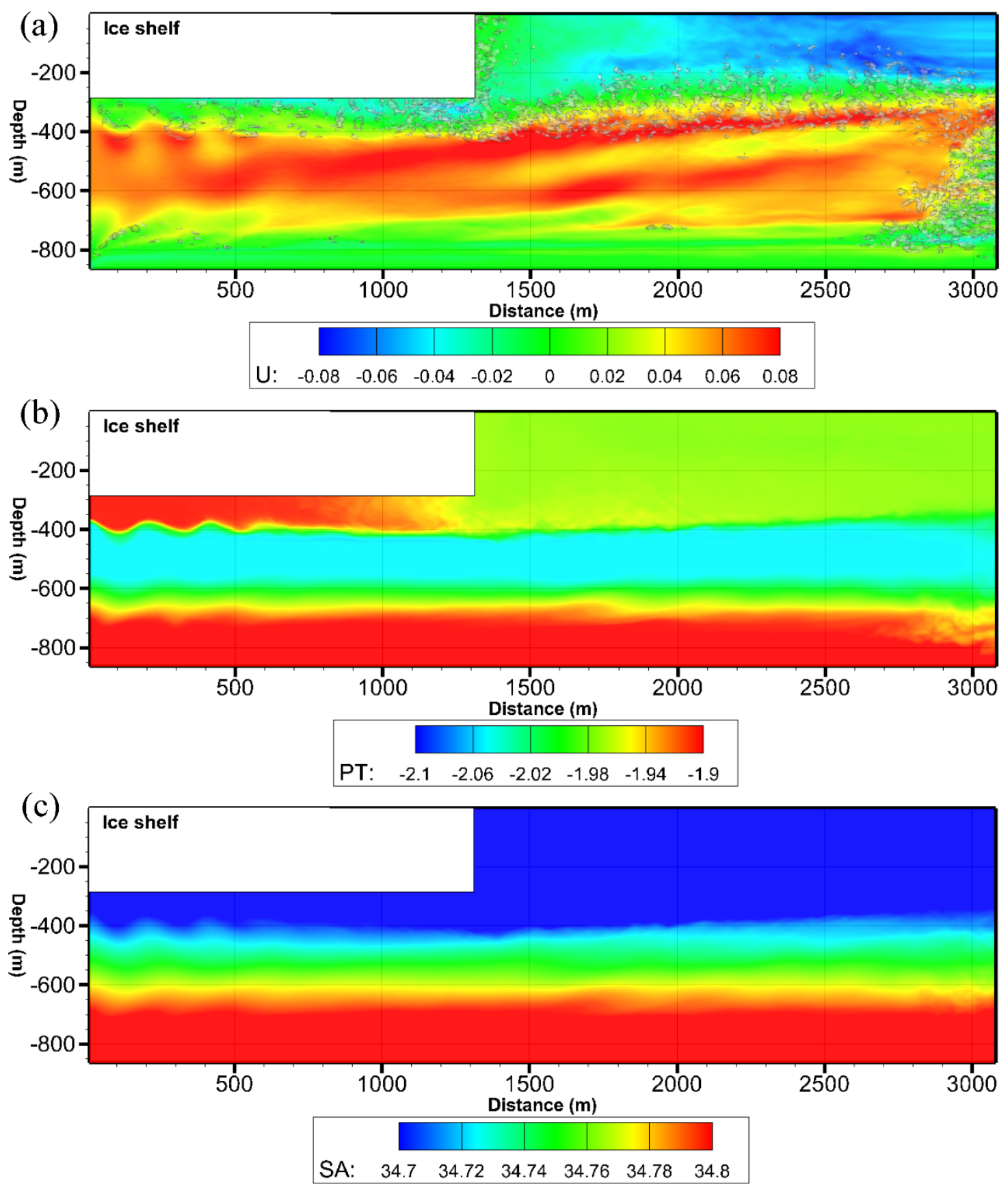

Figure 4: $x z$ cross-section contours $(y=1,536 \mathrm{~m}$, domain center) of velocity (a), potential temperature (b), and salinity (c) in the case without the refreezing effect. 
https://doi.org/10.5194/tc-2020-166

Preprint. Discussion started: 20 July 2020

(c) Author(s) 2020. CC BY 4.0 License.

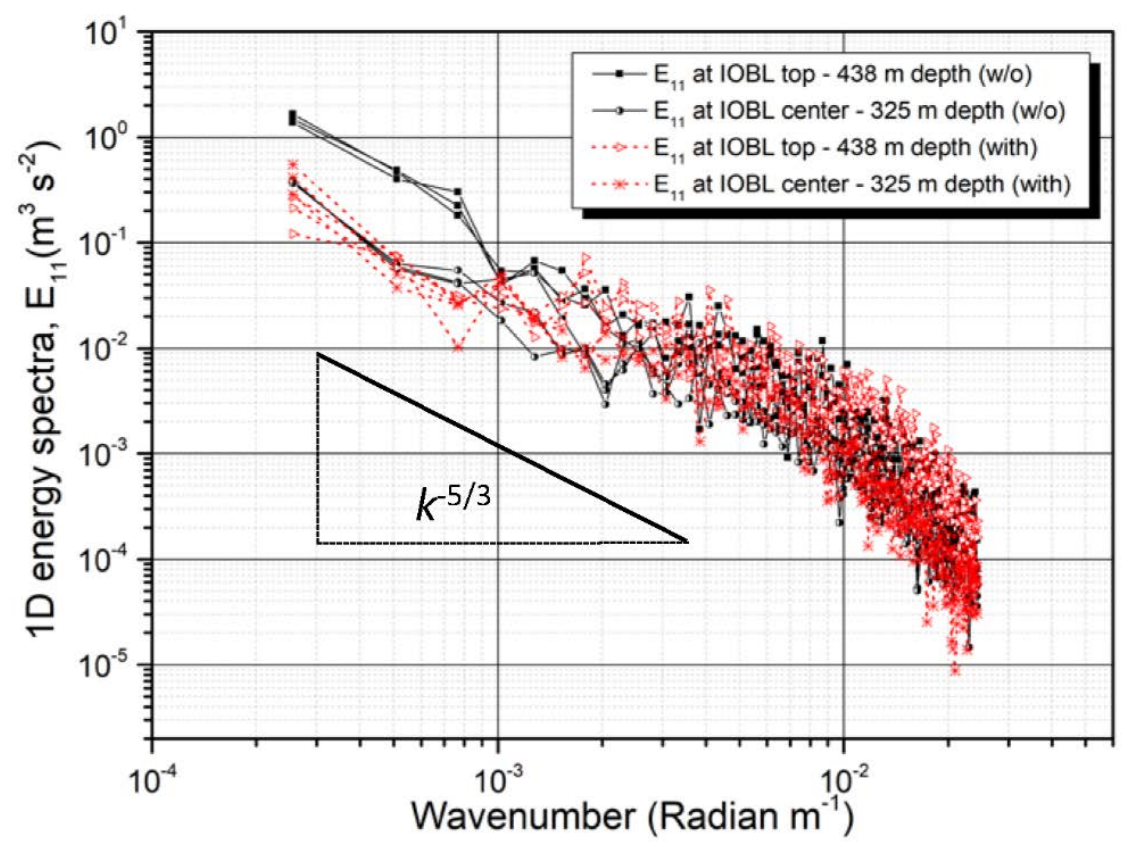

475 Figure 5: One-dimensional turbulence energy spectra at the depths of the ice shelf-ocean boundary layer (IOBL) top (438 m depth) and IOBL center (325 m depth). Black solid features and red dashed features corresponds to cases without and with refreezing, respectively. 
https://doi.org/10.5194/tc-2020-166

Preprint. Discussion started: 20 July 2020

(c) Author(s) 2020. CC BY 4.0 License.
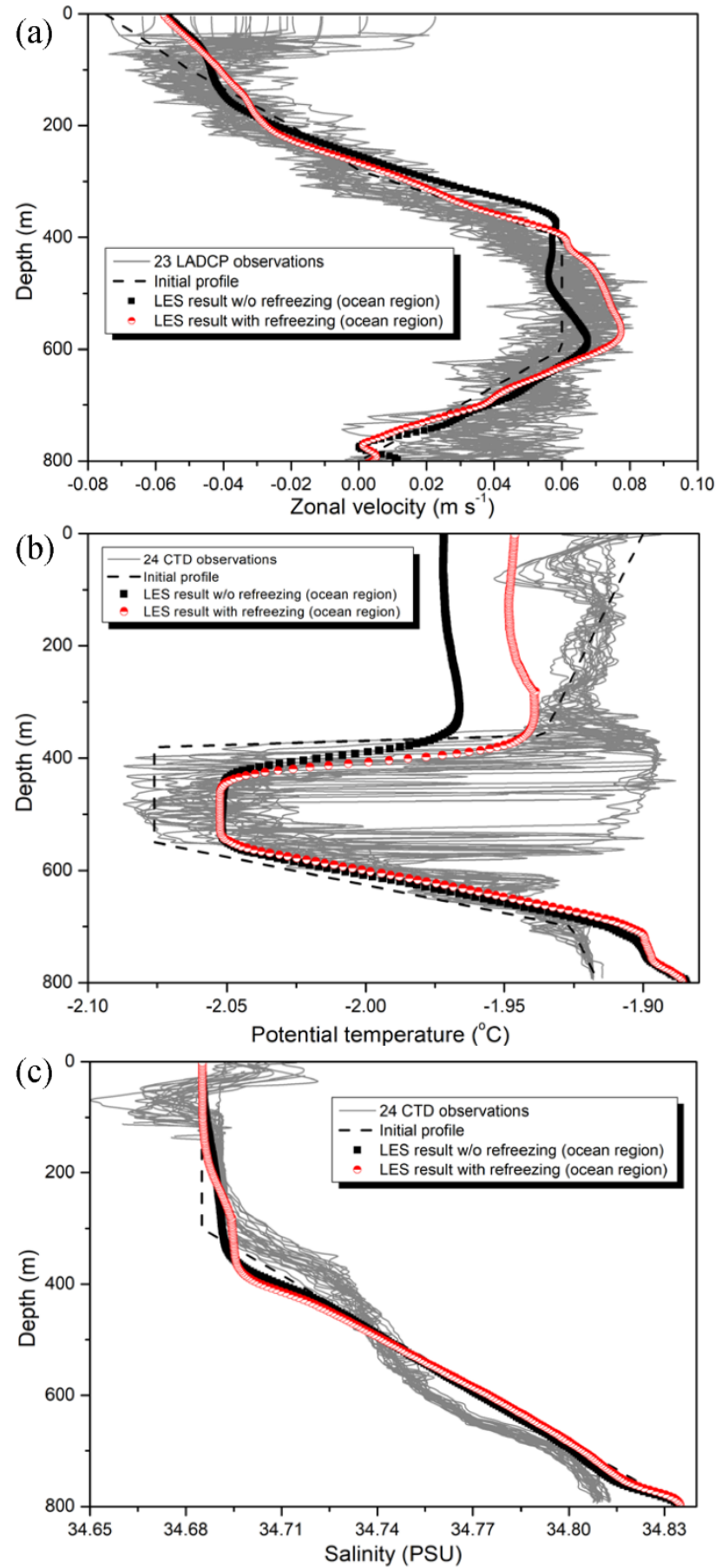

Figure 6: Vertical profiles of velocity, potential temperature, and salinity from the CTD and LADCP observations (solid grey lines), initial profiles (black dashed line), and the results of the large-eddy simulation (LES) without refreezing (black) and with refreezing (red). (a) zonal velocity. (b) potential temperature. (c) salinity. 
https://doi.org/10.5194/tc-2020-166

Preprint. Discussion started: 20 July 2020

(c) Author(s) 2020. CC BY 4.0 License.
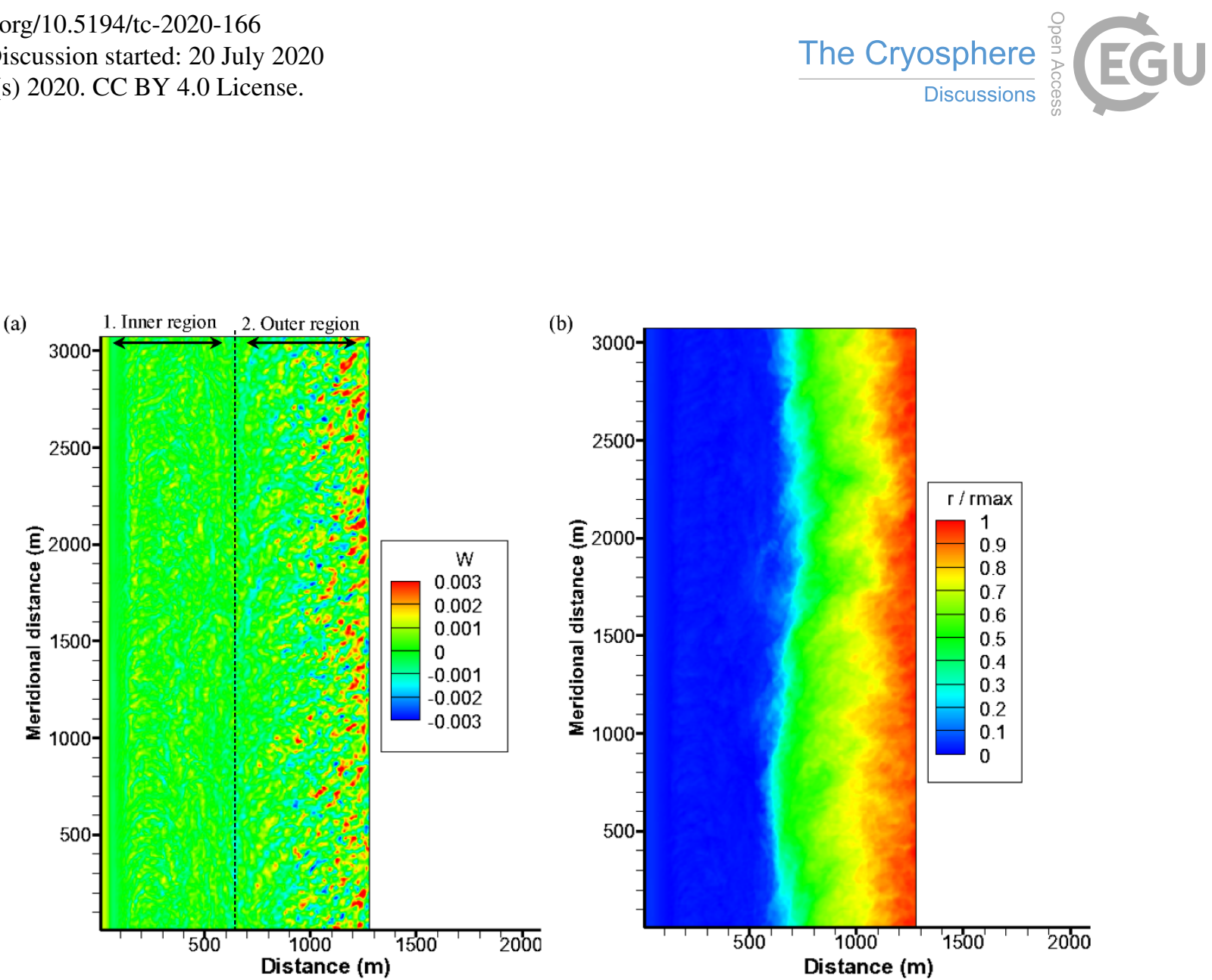

Figure 7: xy cross-section contours (281 $\mathrm{m}$ depth, first node near the ice shelf) of vertical velocity (a) and normalized refreezing rate (b). 
https://doi.org/10.5194/tc-2020-166

Preprint. Discussion started: 20 July 2020

(c) Author(s) 2020. CC BY 4.0 License.

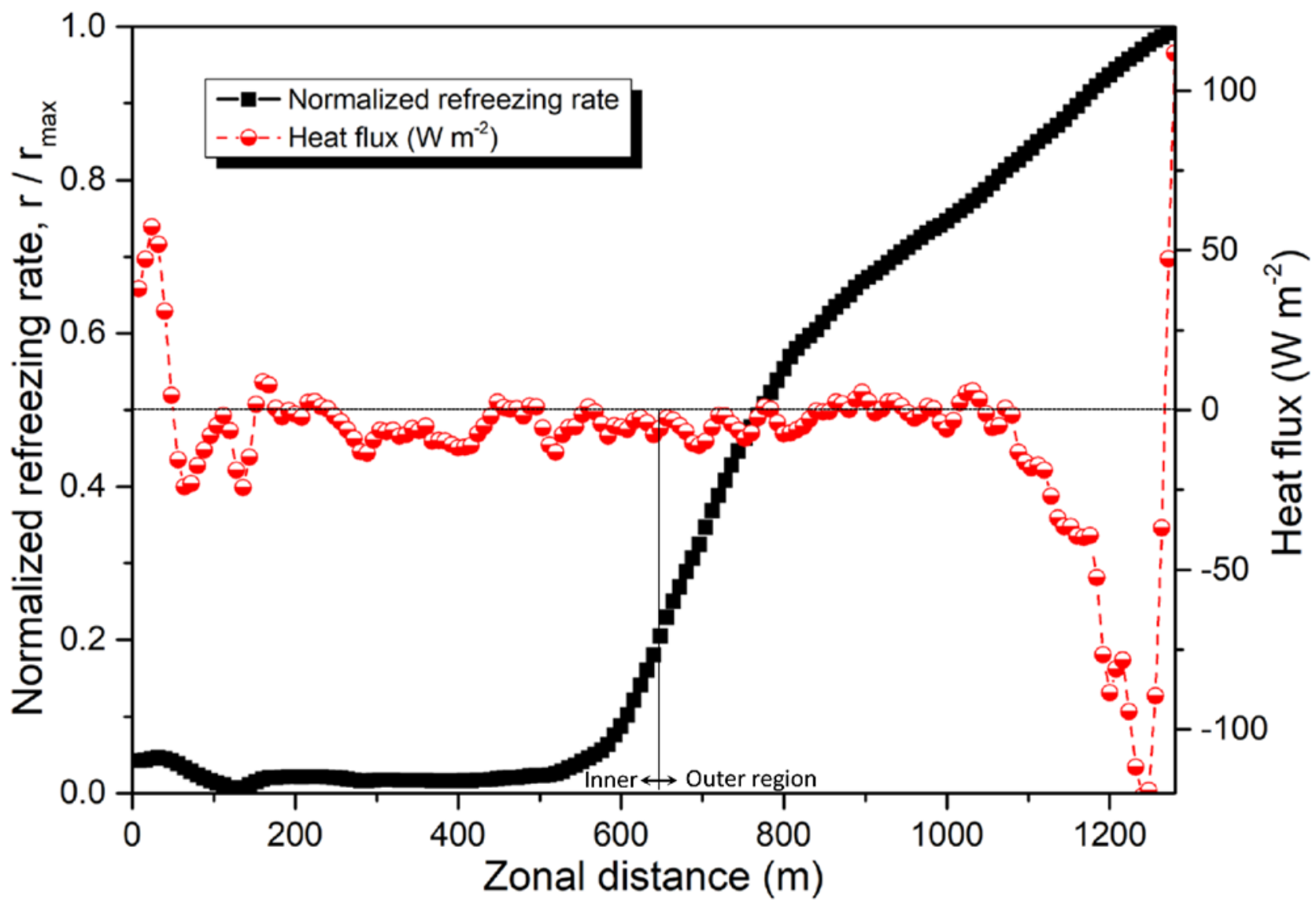

Figure 8: Spatial distribution of heat flux and refreezing rate in the inner and outer regions in the ice shelf. These values are obtained at a depth of $281 \mathrm{~m}$ and are averaged along the meridional direction. 
https://doi.org/10.5194/tc-2020-166

Preprint. Discussion started: 20 July 2020

(c) Author(s) 2020. CC BY 4.0 License.

(a)

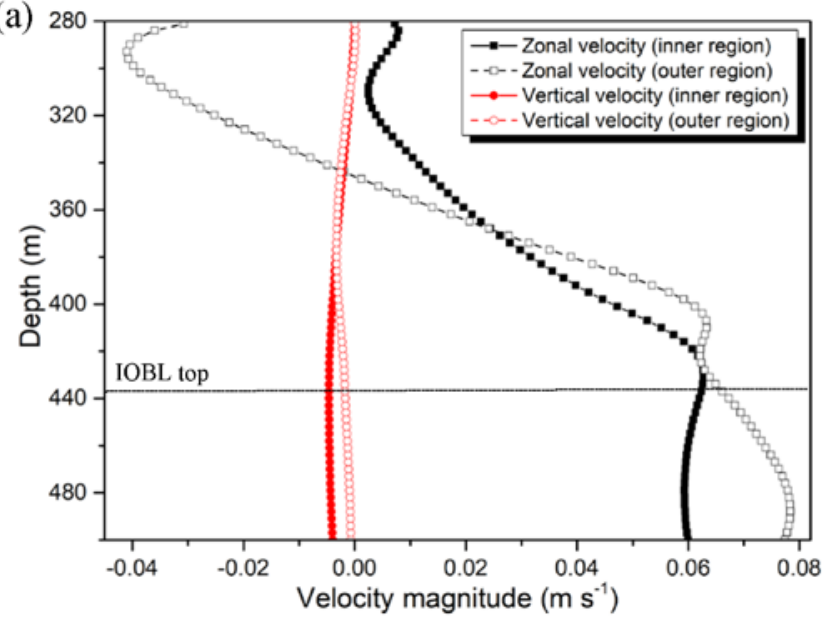

(b)

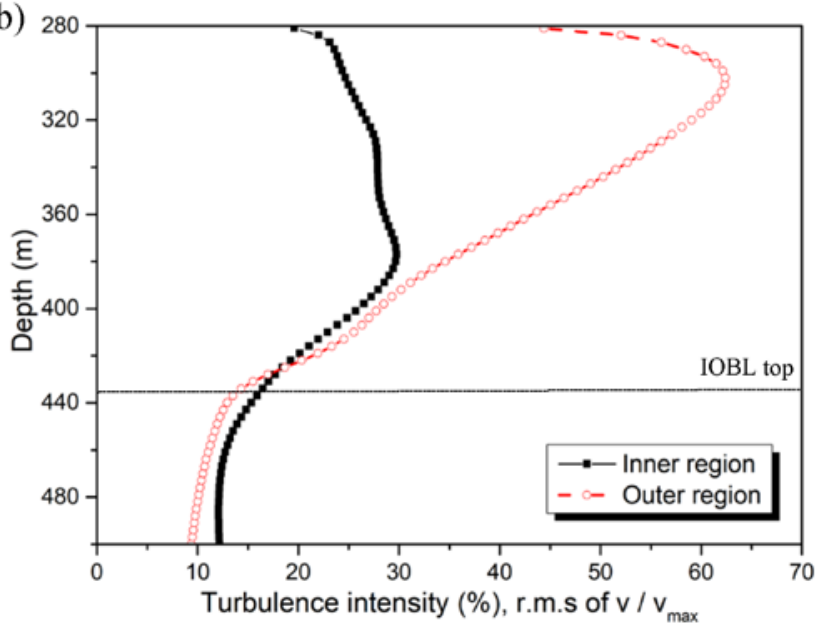

495 Figure 9: Vertical profiles of (a) mean velocities and (b) turbulence intensity. The mean velocities in the inner and outer regions are obtained by averaging the velocity within the $x y$ plane in the inner and outer regions. 
https://doi.org/10.5194/tc-2020-166

Preprint. Discussion started: 20 July 2020

(c) Author(s) 2020. CC BY 4.0 License.

(c) (i)
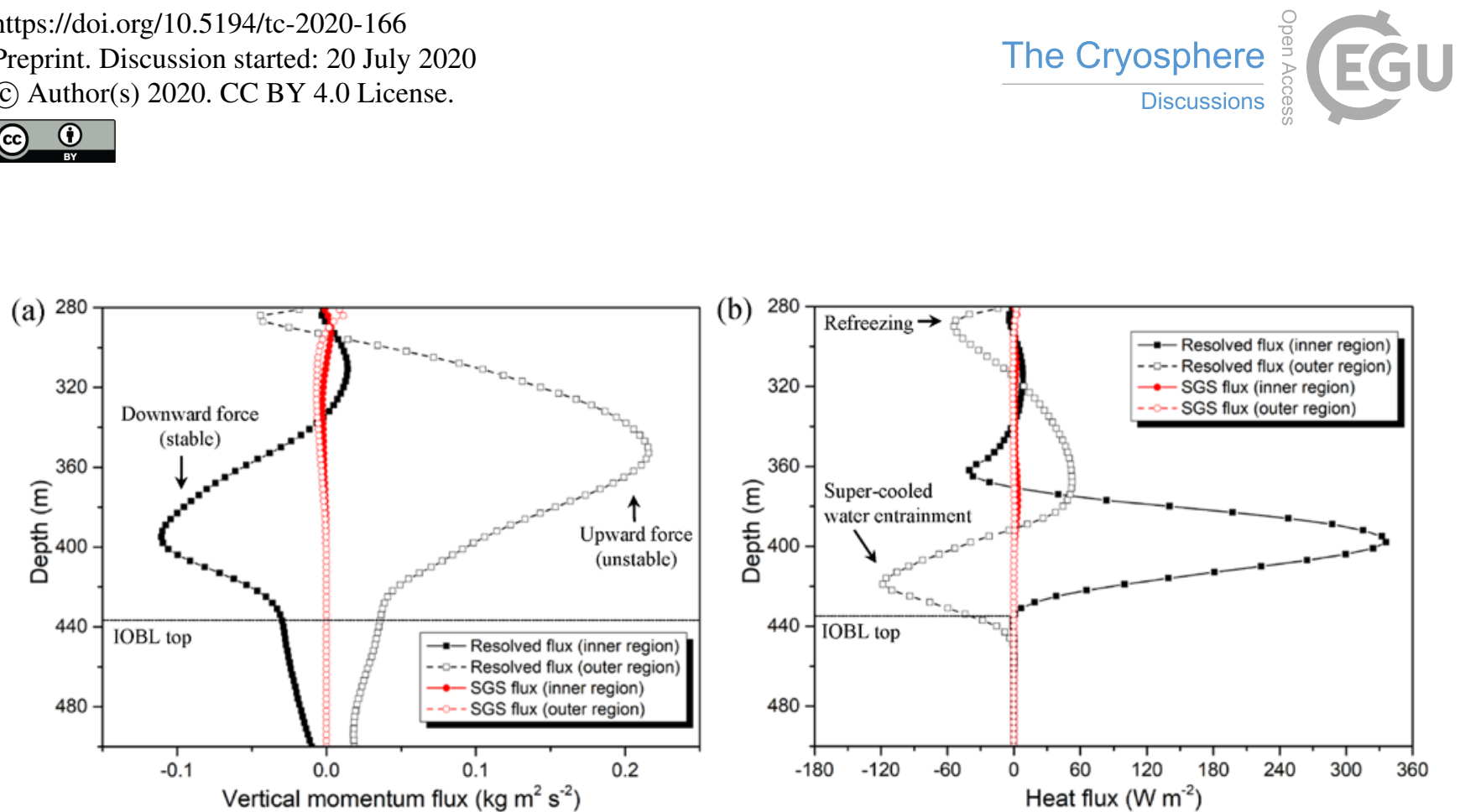

Figure 10: Vertical profiles of momentum fluxes and heat fluxes. Fluxes were characterized using resolved flux and subgrid scale (SGS) flux. (a) Momentum fluxes (resolved: $\rho_{0} \overline{u^{\prime} w^{\prime}}$, SGS: $\rho_{0} K_{m} \overline{\partial u} / \partial z$ ). (b) Heat fluxes (resolved: $\rho_{0} c_{s} \overline{w^{\prime} \theta^{\prime}}$, SGS: $\rho_{0} c_{s} K_{h} \overline{\partial \theta} / \partial z$, where $\rho_{0}\left(1024 \mathrm{~kg} \mathrm{~m}^{-3}\right)$ is the reference density of seawater, and $c_{s}\left(4.02 \times 10^{3} \mathrm{~J} \mathrm{~kg}^{-1} \mathrm{~K}^{-1}\right)$ is the specific heat capacity of seawater (Sharqawy et al., 2010)). 
https://doi.org/10.5194/tc-2020-166

Preprint. Discussion started: 20 July 2020

(c) Author(s) 2020. CC BY 4.0 License.

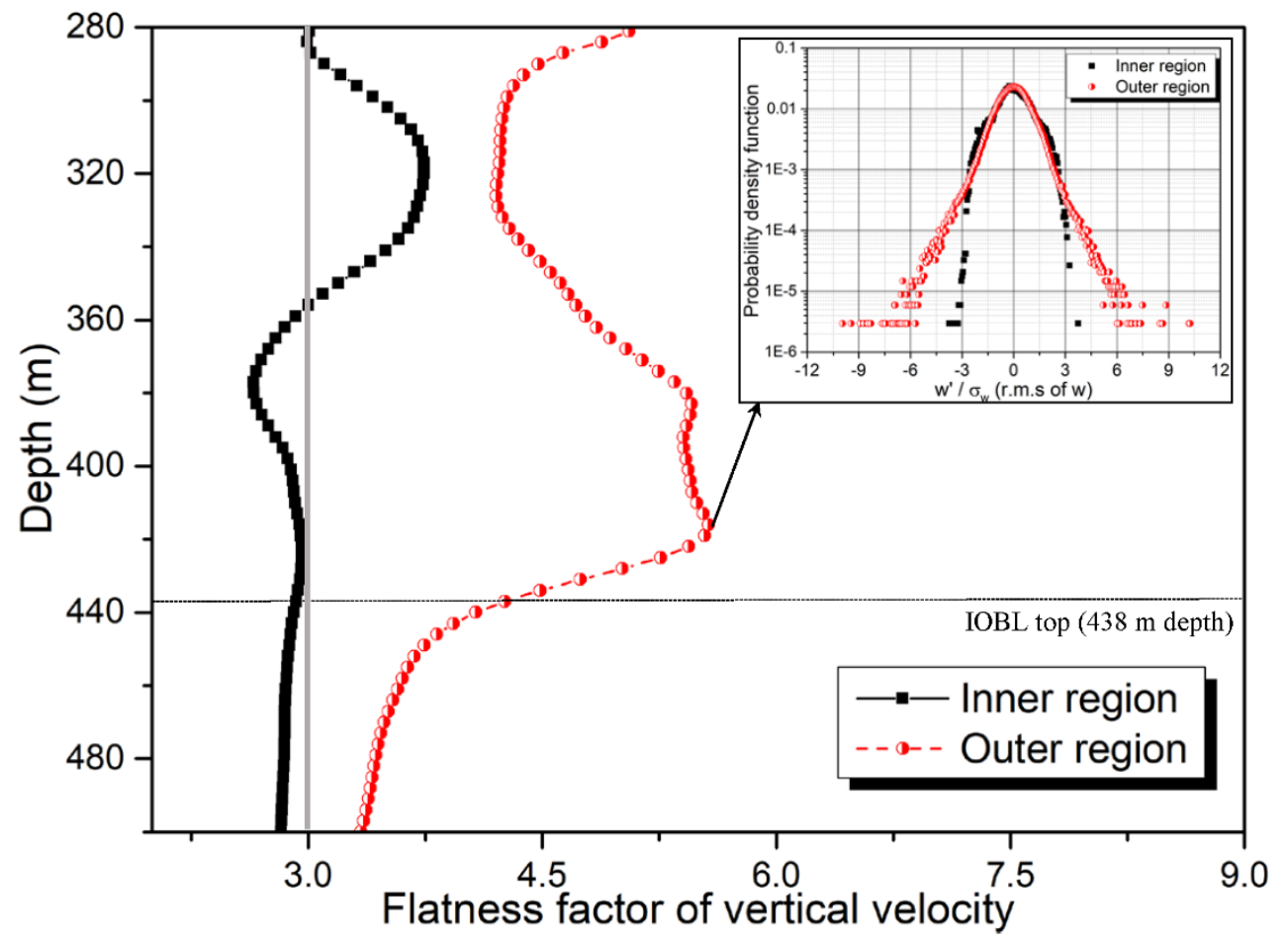

515 Figure 11: Vertical profiles of the flatness factor (Kurtosis) of vertical velocity, $w$. The inset graph is the probability density function at a depth of $416 \mathrm{~m}$ (flatness = 5.56, maximum value). 